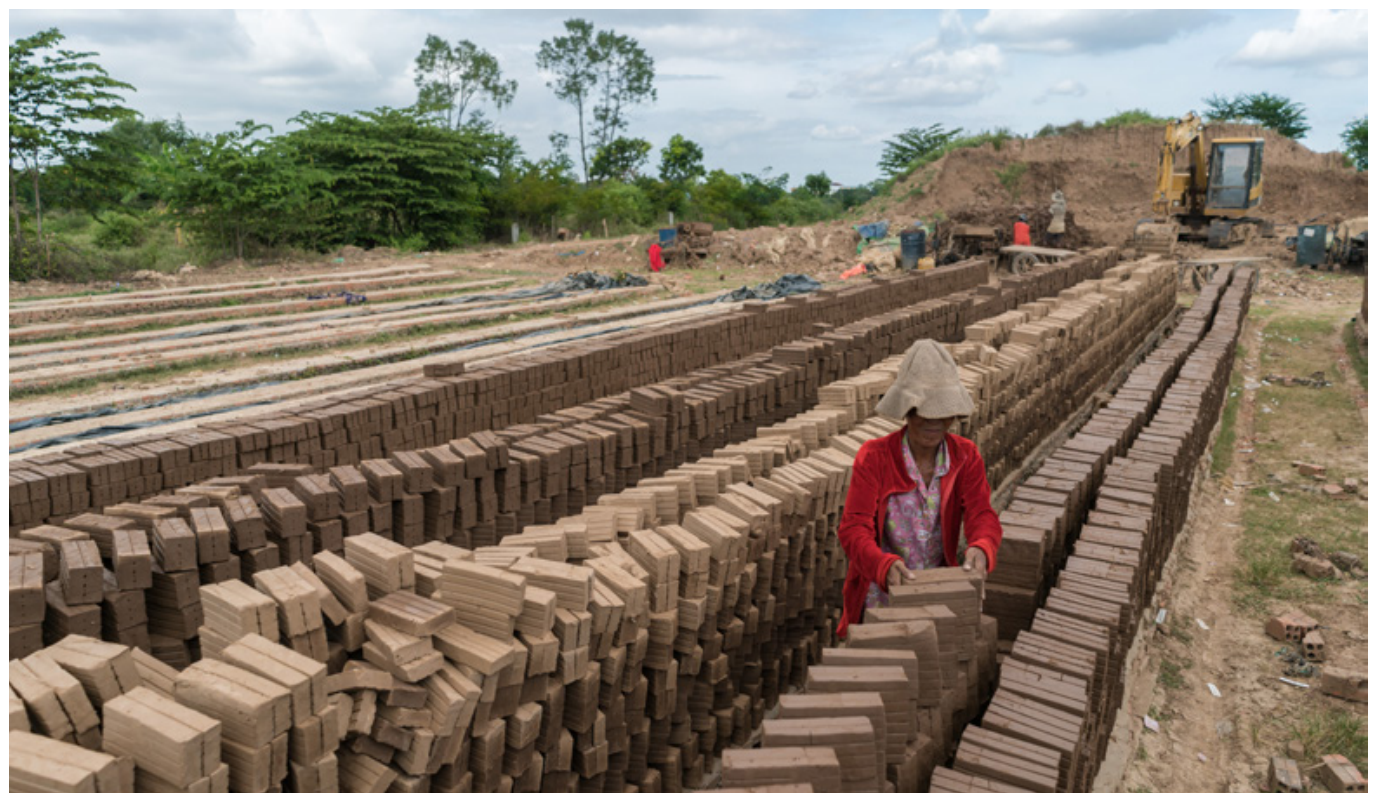

\section{Descending into Debt in Cambodia}

Milford BATEMAN, Nithya NATARAJAN, Katherine BRICKELL, and Laurie PARSONS

Cambodia today is the site of one of the world's largest microcredit sectors. While it is widely believed that the extension of microcredit to Cambodia's poor should be cause for all-round celebration, this essay reveals disquieting evidence of a deeply problematic development intervention. Indebted to microcredit institutions, increasing numbers of Cambodia's poor population have been forced to accept exploitative labour conditions in the garment and construction industry, driven to despair due to the loss of their land, and, in the worst cases, had no choice but to 'sell' themselves as bonded labour to brick kilns owners.
A worker in a brick kiln in the Cambodian countryside. PC: Thomas Cristofoletti
$\mathrm{T}$ he Cambodian economy has undoubtedly been on a roll over the last decade. It has enjoyed several years of rapid growth, exports have risen dramatically, and quite significant progress has been made in reducing poverty (ADB 2018). These important gains might suggest that the country will eventually join the elite club of East Asian 'miracle economies'. An equally remarkable observation, however, relates to the policy model that underpins this apparent success. Given that we know that proactive 'developmental state' policies lie behind the massive economic and social improvements evidenced in East Asia since the end of the Second World War (Johnson 1982; Amsden 1989; Wade 1990), what is so surprising about Cambodia's recent success, especially in terms 
of poverty reduction, is that it appears to have been created by adhering to almost the exact opposite of this 'developmental state' approach: that is, Cambodia appears to have done well in spite of having adopted the standard neoliberal policy model promoted by the World Bank, International Monetary Fund, and Asian Development Bank (ADB).

Since the neoliberal policy package is widely associated with economic and social reversals in almost all adopting countries in the Global South (Chang and Grabel 2014)and is responsible for having piloted the global economy into a wall on Wall Street in 2008 (Mirowski 2013)-this apparent paradox demands an explanation. One must ask how come Cambodia seems to have succeeded with such a problematic, if not fatally flawed, policy model. In fact, the answer is pretty straightforward: Cambodia's much-trumpeted economic success is not quite as sustainable as we think it is, particularly with regard to the issues of Chinese investments in real estate and construction, and free access to markets for Cambodia's garment exports, both of which are in some danger of heading into reverse (World Bank 2018).

The purpose of this essay is to further underline the precariousness of Cambodia's recent economic success through an examination of the most important local neoliberal policy intervention deployed in the country: microcredit. Cambodia's microcredit movement was first established in the early 1990 s as a way of integrating demobilised soldiers back into civilian life. Further growth and, from 2010 onwards, growing injections of foreign investment, have meant that today Cambodia is the site of one of the world's largest microcredit sectors (Bateman 2019a). The Cambodian Microfinance Association's latest data shows, for example, that by April 2018 the total volume of microcredit disbursed stood at more than 4.6 billion USD (CMA 2019), which represents one of the world's highest levels of microcredit penetration per capita.

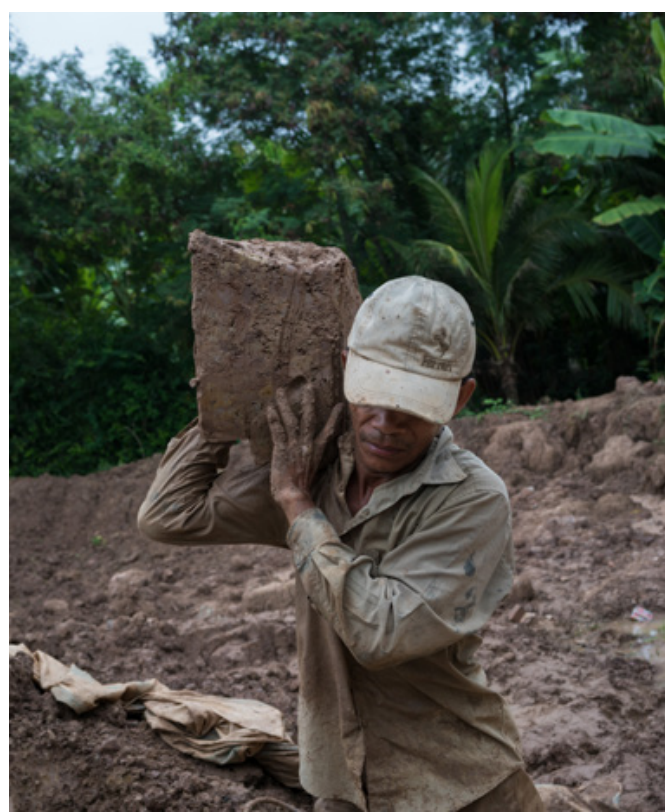

A worker in a brick kiln in the Cambodian countryside. PC: Thomas Cristofoletti

\section{A Cause for Celebration?}

By all accounts, the insertion of microcredit into the ordinary lives of Cambodia's poor over the last 20 or so years should be cause for all-round celebration. As famously argued by Muhammad Yunus, the Bangladeshi economist and co-recipient of the 2006 Nobel Peace Prize, Cambodia's poor and unemployed should have been rapidly escaping poverty thanks to their own entrepreneurial efforts and the creation of many informal microenterprise and selfemployment ventures (Yunus 1989). But this has clearly not happened. Instead, the rise of the microcredit sector in Cambodia has actually created an almost entirely deleterious trajectory for the country's poor. Leaving aside the handful of untypical successful microcredit-funded business projects, looking behind the hype and spin surrounding the 
microcredit industry in Cambodia reveals a mountain of disquieting evidence of a deeply problematic financial intervention.

Let us look first at the fundamentals of microcredit as they apply in Cambodia (and everywhere else, see Bateman 2010). The leading microcredit institutions (hereafter MCIs) in Cambodia consciously adhere to the global microcredit industry's required narrative that an individual's attempt at selfemployment will virtually always succeed. Some of Cambodia's MCIs go so far as to suggest that using their services will allow almost anyone to be successful in some petty business area-as easy as simply picking money from your own money tree! So what can go wrong?

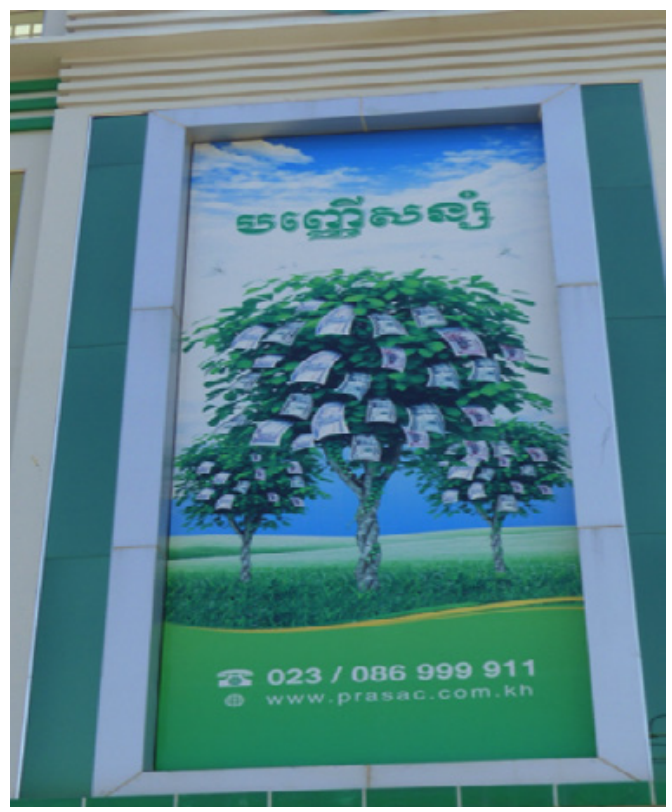

Prasac Microfinance and its 'money tree' advertisement. PC: Billi Glover

There is a flaw in the microcredit model, which has been especially in evidence in Cambodia. This flaw relates to the basic lack of local demand that exists by definition in poor communities (see Bateman 2019b). When virtually everyone in a location is in poverty, instructing poor individuals to escape their own poverty predicament by becoming a microentrepreneur selling something to others in the community makes little sense. This guidance rests on the false assumption that local demand is infinitely elastic and will stretch to cover almost any programmed increase in the local supply of simple goods and services. Economists call this 'Say's Law'-the fallacy that supply will create its own demand. Many economists, most notably Alice Amsden (2010), have argued that it is the basic misunderstanding of this fallacy that ensured almost all anti-poverty programmes in the Global South that attempt to improve the supply-side of the local economy-e.g. through the supply of more credit, more education, more training, etc.-were doomed to failure.

Accordingly, the most visible result of a microcredit programme is that the new microenterprises assisted into operation will find it very tough to find customers. As a consequence, very many will simply fail after a short period of time. Our recent fieldwork in Kampong Cham, for example, found that accounts of unsuccessful business ventures, and repeated unsuccessful attempts to locate 'something that worked', far outweighed the few accounts we heard of successful businesses being formed. Moreover, most of the 'success stories' originated in households with higher levels of wealth and more assets to begin with. Furthermore, even if an individual is one of the very few able to succeed in scraping together enough clients to keep their business going, they inevitably end up eating into the incomes and jobs of the already existing microenterprises in the community with which they enter into competition. That is, jobs and incomes in already struggling incumbent microenterprises are displaced by new entrants.

Economists call this entry and exit phenomenon 'job churn' and in Cambodia it represents an almost unsurpassable barrier to the real creation of additional jobs and incomes. When the level of competition for the 
limited demand for simple items and services in most rural areas is now simply off the scale, encouraging others to enter the very same markets has little to recommend it. The rows of street stalls attracting very few passersby, woefully under-used tuk tuks, and eerily vacant food outlets all testify to the programmed over-supply of such services in so many of the villages in rural Cambodia.

Seriously compounding this problem is the fact that small-scale agriculture in Cambodia is now so unproductive that very few of those accessing microcredit to develop an agricultural enterprise can repay the loans. The absence of irrigation, extension services support, storage facilities, marketing programmes, and other forms of important infrastructure in the rural areas of Cambodiainfrastructure that everywhere else in East Asia enabled small-scale farming to flourish (see Studwell 2013, 1-56)-has inevitably led to a seriously unproductive agricultural sector in the country. As reported by Aleem (2018), rather than remaining in the village to work on a wholly unprofitable agricultural venture, the young-representing a demographic dividend in the current era with 60 percent of the country's population aged 30 or under (Phnom Penh Post 2019)-are increasingly forced to move into the main Cambodian urban areas and cities, or even further afield, in search of a living. It is either that, Aleem goes on to argue, or the taking out of many more microloans by the farming community in a desperate effort to survive for a few more years, which is one of the principal causes of the high levels of rural debt.

In fact, the phenomenon of labour wages being used to repay a microloan has become so ubiquitous that MCIs are lending even to those villagers without any agricultural land. We certainly saw widespread evidence of this during recent fieldwork in Kampong Cham. Numerous households had used the land title of the small plot on which their family house-a structure representing particular significance given Cambodians' strong ties to their natal villages-was built as collateral for microloans of 1,000 USD, 2,000 USD, and even more. As such, households were stretching themselves beyond belief to repay these microloans, given the terrifying possibility of losing their family house upon default, and the phenomenon of grandparents caring for grandchildren whilst parents laboured for months or years elsewhere was not uncommon.

\section{Growing Worries}

With virtually all possibilities to realise a decent living from a microenterprise or from small-scale agriculture now choked off, resulting in the poor purposely taking out microloans for other purposes entirely-e.g. for healthcare costs (see also below)-it is not surprising that so many of the poor in Cambodia have descended into quite dramatic levels of debt. This development is seen in almost all local communities outside of the capital Phnom Penh. Liv (2013) was one of the first to report on the serious rise in household indebtedness in several locations. The ADB (2014,14-15) was also forced to report on the 'high and potentially underreported level of indebtedness among the poor and the significant share of loans of an unproductive nature [which] suggest that the issue of vulnerability is more significant than existing poverty analyses recognise'.

Most recently, growing worries about the sustainability of their hugely profitable investments into Cambodia's microcredit sector has led a number of leading 'social impact' investors to seek out their own data on the industry's over-indebtedness problem (MFC et al. 2017). This initially confidential report, later widely leaked to local journalists, essentially confirmed almost all of the most deleterious trends openly raised by other analysts (for example, Bateman 2017a). While repeatedly claiming that 'market saturation has not yet been reached', the report nevertheless painted a very bleak picture of the impact of microcredit. Notably, it underlined the myriad of ways the poor in Cambodia are desperately 
trying to repay their growing debts. On page 9, for example, it pointed out that: 'Borrowers use different strategies to repay loans such as depleting their savings, asking their families for financial help, working overtime or adjusting food consumption.' This effectively means that the poor are doing anything other than using the income from a functioning microenterprise to repay their microloan, thus contravening the entire rationale behind the microcredit model.

An even more worrying aspect highlighted in the report is the dramatic rise in what is known on Wall Street as 'extend and pretend'-the trick of keeping poor clients on an indefinite debt treadmill, always reoffering a new microloan or rescheduling an existing one, but maintaining the repayment at the current level by simply lengthening the terms of the microloan. On page 33 , it is reported that ' $46 \%$ of active borrowers renewed loans from the same institution at maturity'. And then on page 41 we find that ' $66 \%$ of ... borrowers who prepaid their loans, that is $15.5 \%$ of all borrowers, took another one within the next 30 days' and that '[in] most cases, the new loan was larger, especially when it was taken right after the early repayment (next disbursement within 30 days).' This means that the leading MCIs are encouraging their poor clients not just to take on microcredit in perpetuity, but to refinance a microloan even before an existing microloan is repaid. As presumably intended, this allows the MCI to apply the usual charges associated with refinancing a microloan (fees, document charges, etc.) but also-crucially-it allows for the loan value to increase over a longer time period so that the client goes into even deeper debt to the MCI. In our fieldwork, we found many of those signing up for a new loan did so because the monthly repayment stayed the same and they got some cash in hand all without even realising that the length of the microloan had increased.

Thanks to all of these negative trends, the dominant method of repaying microloans in Cambodia today is not through the profits earned by microentrepreneurs through their own microcredit-assisted microenterprise, but increasingly thanks to the labour of other family members. Two such categories are predominant. First, family members working in the garment factories in Phnom Penh are often required to remit substantial amounts to their family members so they can repay microloans. In many cases, the initial capital required to obtain a position in one of the factories itself necessitates the obtaining of microcredit. Second, as extensively detailed by Bylander (2015), a growing number of overindebted individuals in Cambodia are forced to migrate to neighbouring Thailand to work in the informal sector in order to generate the funds to repay their microloans.

Those that fail to generate funds through migration are forced to seek out funds from other even less beneficial sources. Pointedly, given that formal microcredit was supposed to displace traditional moneylending (Yunus and Jolis 1998), many poor individuals have been forced to return to local moneylenders in their communities to obtain funds to keep a microcredit repayment schedule intact (see Ovesen and Trankell 2014), a phenomenon that we noted in our recent fieldwork. Contrary to the views of many microcredit advocates and lobbyists (for example, Rozas 2017), the rapid growth of formal microcredit, and subsequent mass over-indebtedness of the poor population, has provided a major shot in the arm for local moneylenders.

\section{Landlessness and Debt Bondage}

One other important question then comes to mind here: why are the leading MCIs indulging in so much reckless lending that surely risks a wave of defaults? The answer to this lies in the fact that the MCIs make sure to obtain collateral in the form of a land certificate. Unlike any other country in the Global South, where microcredit has been premised on joint-liability loan groups rather than physical collateral, Cambodian microloans 
are underwritten by the poor's single most valuable asset-their land. Furthermore, as noted earlier, this is not only agricultural land but also the very land on which their house sits. Losing one's land anywhere in the Global South all too often means a descent into irretrievable poverty and destitution, so the incentive to avoid default at all cost is naturally significant.

In extreme cases, recent evidence from Cambodia highlights how indebted rural households will even choose to become debtbonded labourers on one of Cambodia's proliferating brick kilns in order to avoid default and the concomitant land loss (Brickell et al. 2018). This involves approaching a kiln owner and asking them to pay-off MCI and informal lender debts in the village in exchange for a consolidated debt bond. The whole nuclear family then moves to live-and undertake gruelling and unsafe work-on the site of a brick kiln, with their mobility restricted until the debt is repaid. The existence and even increasing use of this strategy by indebted rural households certainly speaks to the lengths they will go to in order to avoid default, and the power MCIs hold over them in using household land as collateral.

Notwithstanding, it seems that many poor individuals do not succeed in repaying their microloans and, as a result, a number have ended up losing their family land. While the legality of land transfer in Cambodia is complicated-and it is seemingly difficult for an MCI to obtain land for on-sale through the default route-the actual practice is that informal transfers of land are very common. Often the MCI's loan officer simply brings the village chief, the debtor, and a willing buyer for the debtor's land together and (usually for a fee) he encourages a private sale without too much fuss. At other times the process is carried out at a larger scale with poor populations being seriously disadvantaged. For example, Kurczy (2009) reported from a village in Kampot province in southern Cambodia where a bad harvest meant that a large group of villagers risked losing their land to the local MCIs from which they had obtained microcredit using their land certificate as collateral. In order to avoid default, an attempt was made by the villagers to keep repaying at least part of what they owed by tapping into funds from the local informal moneylender. But when this tactic proved unworkable, all of the land plots were eventually seized by the MCIs.

Anecdotes aside, overall figures for such land loss are hard to come by. Given the political sensitivity of financial institutions exploiting the poor in such a manner, this is not unexpected. However, Steptoe (2013)quoting a leading expert on the legalities of rural development, Mounh Sarath-writes that until 2012 perhaps as much 10-15 percent of Cambodia's rural land had been seized from the poor through this process. Moreover, this adverse trend appears to have continued in recent years, as land is increasingly demanded for a number of commercial purposes and land titles are now far more common than before. For example, Grimsditch and Schoenberger (2015) point out that the land-loss process has been significantly accelerated in recent years as a result of a land titling project begun in 2012 with the aim of providing land titles to as many as 400,000 families living on state land. At any rate, the land-loss issue remains a sensitive one and it is likely to continue seriously undermining the already precarious lives of Cambodia's poor.

\section{To Whose Advantage?}

The final issue to consider here relates to the crucial question of who has really benefitted from the growth of the microcredit sector in Cambodia, which is now probably the world's most profitable. Initially structured as NGOs, it only really became clear how much profit could be made in the microcredit sector when ACLEDA, then Cambodia's largest MCI (it is now the country's largest commercial bank), hived off a portion of its equity (12.25 percent) to a major Hong Kong-based investment house, Jardine Matheson Holdings, for 34 million USD. 
When this equity stake was sold for 166 million USD just six year later, realising a massive 30 percent annual rate of return, the die was cast (Bateman 2017a). Since then all of Cambodia's leading MCIs have been bought up by foreign investors. In terms of yearly dividends and the eventual capital appreciation, the amount of capital transferred to these new foreign owners has been quite considerable.

Indeed, it was precisely the fear of losing just a small part of their massive profit flow that spooked the leading foreign-owned MCIs into an aggressive fight back against the Cambodian government's proposed imposition of an 18 percent interest rate cap on new and refinanced microloans beginning on 1 April 2017. Fearing their profits would be reduced, local MCIs, investors, and many others began working frantically to lobby the authorities to change this new regulation. Some even argued that a widespread microcredit shortage would ensue if the proposed interest rate cap was imposed (Rozas 2017). However, events quickly proved these claims to be no more than scare tactics: the supply of microcredit actually continued to rise, while profits at the largest MCIs have been largely unaffected (Bateman 2017b).

However, with significant value continuing to flow out of Cambodia in the form of dividends and capital appreciation, it is clear that the country is losing a considerable amount of local spending power. As a result, an entirely quixotic situation has arisen: at a time when the international donor community is supporting so many 'buy Cambodian goods' initiatives targeted at wealthier local Cambodians and wealthy foreign tourists aimed at keeping capital within the country, the foreign investors that today own and manage the most important MCIs are extracting stratospheric returns from those same communities. An hour or so spent at the 'Made in Cambodia' market in Siem Reap, for example, shows that many of the local businesses operating there have been supported by various international development community programmes, which all encourage visitors to 'help the poor by buying something made locally by the poor'.
But there are no such signs asking the MCIs to consider not taking their massive financial gains out of Cambodia and instead spend this largesse on local businesses operated by the poor.

As elsewhere in the Global South today (Bateman et al. 2019), the failure of Cambodia's microcredit sector to genuinely address the country's poverty and development problems is a disaster for the country's poor, as well as a very serious indictment of the neoliberal local policy model that has been impressed upon successive Cambodian governments since the 1980s. A litany of negative impacts associated with the microcredit model have combined to seriously offset the other more positive, but still transient, gains registered of late. Worse, there are few optimistic portents pointing to a coming reversal of the negative trends. 